\title{
Avaliação do potencial antimicrobiano de Plinia glomerata (Myrtaceae)
}

\author{
Claudia Serafin ${ }^{1}$, Viviane Nart ${ }^{1}$, Angela Malheiros ${ }^{1}$, Alexandre Bella Cruz ${ }^{1}$, Franco Delle \\ Monache $^{1}$, Maria de los Angeles Gette ${ }^{2}$, Susana Zacchino ${ }^{2}$, Valdir Cechinel Filho ${ }^{1 *}$ \\ 'Programa de Mestrado em Ciências Farmacêuticas, Núcleo de Investigações Químico-Farmacêuticas, \\ Universidade do Vale do Itajaí, Rua Uruguai 458, 88302-202, Itajaí, SC, Brasil, \\ ${ }^{2}$ Área de Farmacognosia, Faculdade de Farmácia e Bioquímica, Universidad Nacional de Rosário y de San Luis, \\ Rosario e San Luis, Argentina
}

\begin{abstract}
RESUMO: A planta Plinia glomerata (Myrtaceae), popularmente conhecida como cabeludinha ou "jabuticaba-amarela", ocorre amplamente no sul do Brasil e é cultivada como ornamental e frutífera comestível. O presente trabalho avaliou as propriedades antimicrobianas dos extratos, frações e substâncias puras isoladas da planta contra bactérias e fungos patogênicos. As concentrações inibitórias mínimas (CIM) foram determinadas através do método de diluição em ágar. As frações acetato de etila (AE) e fração aquosa (AQ) demonstraram a melhor atividade contra Staphylococcus aureus. A fração AQ também foi efetiva contra Escherichia coli. As substâncias puras, ácido 3,4,3'-trimetóxi-flavelágico-4'-O-glicosídeo e ácido 3,4,3'-trimetóxiflavelágico foram inativas até a concentração de $500 \mu \mathrm{g} / \mathrm{mL}$ contra os microrganismos testados. Em relação aos resultados antifúngicos, os extratos metanólico (EM) e acetônico (EA) e a fração aquosa (AQ) mostraram boa atividade somente contra dermatófitos. Os resultados obtidos permitem concluir que a Plinia glomerata possui princípios ativos com ação antimicrobiana, sugerindo que outras substâncias da planta estão agindo contra os microrganismos indicados ou a existência de efeitos sinérgicos.
\end{abstract}

Unitermos: Plinia glomerata, atividade antimicrobiana, ácido 3,4,3'-trimetóxi-flavelágico-4'O-glicosídeo, ácido 3,4,3'-trimetóxi-flavelágico.

\begin{abstract}
Evaluation of the antimicrobial effects of Plinia glomerata (Myrtaceae)" Plinia glomerata, commonly known as "yellow jaboticaba" or "cabelluda" occurs widely in south of Brazil. This work evaluated the antimicrobial properties of the extracts, fractions and isolated compounds of this plant against pathogenic microorganisms, bacteria and fungi. The minimal inhibitory concentration (MIC) was determined through the method of dilution in agar. The ethyl acetate (EtOAc) and aqueous fractions demonstrated the best activity against Staphylococcus aureus. The aqueous fraction also exhibited good activity against Escherichia coli. The pure substances 3,4,3'-trimethoxy-flavellagic-4'-O-glucose acid and 3,4,3'-trimethoxy-flavellagic acid were inactive up to $500 \mu \mathrm{g} / \mathrm{mL}$. Regarding results against fungi, EA and EM extracts as well as AQ fraction showed good activity only against dermatophytes. The results suggest that $P$. glomerata produces active principles with antimicrobial activity, suggesting that other substances from the plant are acting against the microorganisms or the existence of synergic effects.
\end{abstract}

Keywords: Plinia glomerata, antimicrobial activity, 3,4,3'-trimethoxy-flavellagic-4'-O-glucose acid, 3,4,3'-trimethoxy-flavellagic acid.

\section{INTRODUÇÃO}

A família Myrtaceae, de significativa ocorrência no sul do Brasil, é formada por um grande número de plantas que incluem desde matas rasteiras a grandes árvores. Esta família é considerada uma das mais importantes da mata Atlântica brasileira. $\mathrm{O}$ potencial medicinal de muitas de suas espécies tem sido experimentalmente comprovado, como a atividade anti-reumática, antidiabética, antimicrobiana, diurética e reguladora do sistema digestivo, entre outras, comprovados em diferentes modelos experimentais
(Gibbons, 2003; Barbosa-Filho et al., 2005; Morais et al., 2005; Vendruscolo et al., 2005; Amaral et al., 2006; Bezerra et al., 2006; Bnouhom et al., 2006; Agra et al., 2007; Oliveira et al., 2007).

A Plinia glomerata, é conhecida popularmente como "cabeludinha" ou "jabuticaba-amarela", e possui também como nome científico Myrciaria glomerata, Eugenia cabelluda e Eugenia tomentosa. A espécie é nativa do Brasil, originária dos estados de Rio de Janeiro, São Paulo e parte sul de Minas Gerais (Cabeludinha, 2005). São raros os estudos com esta espécie, sendo encontrado apenas um trabalho preliminar indicando 
efeito de seu extrato contra $S$. aureus, $P$. aeruginosa e Burkholderia cepacia. (Silva et al., 2000). Recentemente demonstramos a existência de grande potencial analgésico para esta planta, relacionado com a presença de substâncias fenólicas (Serafin et al., 2007). O presente trabalho analisa a atividade antimicrobiana dos extratos, frações e substâncias puras obtidas das partes aéreas de Plinia glomerata contra microrganismos patogênicos (fungos e bactérias).

\section{MATERIAL E MÉTODOS}

\section{Procedimentos gerais}

Todas as frações foram submetidas a cromatografia em camada delgada (CCD), onde utilizaram-se placas de cromatografia de sílica Gel $60 \mathrm{~F}_{254}$ adquiridas da Merck, como fase estacionária e diversos eluentes como fase móvel (clorofórmio, metanol, hexano e acetato de etila), variando o tipo e a proporção conforme o comportamento cromatográfico da fração analisada.

Para revelar as classes das substâncias, foi utilizado Ultra-Violeta como revelador universal, e anisaldeído sulfúrico e cloreto férrico $3 \%$ como reveladores específicos. As frações com melhores rendimentos foram submetidas a procedimentos de cromatografia em coluna (CC), onde utilizou-se sílica Gel 60 (70-230 mesh) ou Sephadex LH-20.

As substâncias puras foram identificadas por métodos espectroscópicos usuais: Infra-vermelho (IV - BOMEM-100), ressonância magnética de hidrogênio $\left(\mathrm{RMN}{ }^{1} \mathrm{H}\right)$, carbono $13\left(\mathrm{RMN}{ }^{13} \mathrm{C}\right)$, NOE dif. e HETCOR - (Variam XL-300) e espectroscopia de massas (Thermo Finnigan LCQ Deca XP plus íon trap spectrometer).

\section{Material vegetal}

As partes aéreas (folhas e galhos) de Plinia glomerata foram coletadas na Epagri/Itajaí-SC, Brasil, em dois momentos: outubro de 2004 e setembro de 2005, e sua excicata está depositada no Hebário Barbosa Rodrigues sob $\mathrm{n}^{\mathrm{o}}$ VC Filho 52. Na primeira coleta, o material foi seco em estufa a $40{ }^{\circ} \mathrm{C}$, e posteriormente moído $(0,4 \mathrm{~kg})$. Na segunda coleta, foram utilizadas as folhas e galhos frescos da planta $(1,7 \mathrm{~kg})$.

\section{Preparação dos extratos, frações e isolamento das} substâncias

O material vegetal (folhas e galhos) seco $(0,4$ $\mathrm{kg}$ ) coletado no primeiro momento foi macerado em metanol por sete dias em um percolador. Após este período, o macerado foi filtrado, recolhido e em seguida, concentrado em evaporador rotatório sob pressão reduzida até a secura, obtendo-se o extrato metanólico bruto (EMB) (48 g), dos quais foram reservados cerca de
5 gramas para os testes biológicos. O extrato foi suspenso com mistura de metanol e água $(2: 1)$ e posteriormente particionado sucessivamente com os solventes de polaridade crescente hexano, diclorometano e acetato de etila na proporção $2: 1$, obtendo-se as respectivas frações: Hexano (Fr. Hex) 1,1 g, Diclorometano (Fr. DCM) 0,49 $\mathrm{g}$, acetato de etila (Fr. AE) 0,84 g, sendo que o material restante foi denominado fração aquosa (Fr. AQ), propiciando desta forma, a separação das substâncias conforme suas distintas polaridades (Cechinel Filho; Yunes, 1998; Niero et al., 2003).

$\mathrm{Na}$ segunda coleta, em virtude da pequena quantidade de material obtido na primeira coleta, o material vegetal fresco foi macerado em acetona por 3 dias. Após este período, o filtrado foi concentrado em evaporador rotatório sob pressão reduzida até a secura, obtendo-se $110 \mathrm{~g}$ do extrato acetônico (EA). Em seguida, o mesmo material vegetal foi macerado em metanol por mais 7 dias. Após, foi concentrado em evaporador rotatório sob pressão reduzida onde obtevese $60 \mathrm{~g}$ do extrato metanólico (EM). Cerca de 30 gramas do extrato acetônico foi cromatografado usando-se coluna de sílica gel e fase móvel $\mathrm{CHCl}_{3}: \mathrm{MeOH}$ com aumento de polaridade, resultando $150 \mathrm{mg}$ de ácido 3,4,3'-trimetóxi-flavelágico-4'-O-glicosídeo (1) e 139 mg de ácido 3,4,3'-trimetóxi-flavelágico (2), conforme anteriormente descrito (Serafin et al., 2007).

$\mathrm{O}$ extrato EMB e as frações Hex, DCM, AE e $\mathrm{AQ}$, além dos compostos puros $\mathbf{1}$ e $\mathbf{2}$, foram analisados contra bactérias (Tabela 1), e os extratos EM e EA, além da fração AQ e compostos 1 e 2, foram testados contra fungos (Tabela 2).

\section{Atividade antimicrobiana}

\section{Microrganismos e meios}

As bactérias utilizadas como cepas padrões foram: Escherichia coli (ATCC 11775), e Staphylococcus aureus (ATCC 6538P), fornecidas pela "Fundação Tropical de Pesquisa e Tecnologia André Tosello", Campinas, SP. Os fungos leveduriformes foram: Candida albicans (ATCC 10231), Candida tropicalis (ATCC 7349), Cryptococcus neoformans (ATCC 32264) e Saccharomyces cerevisiae (ATCC 9763); os fungos filamentosos foram: Aspergillus flavus (ATCC 9170), Aspergillus fumigatus (ATCC 26934), Aspergillus niger (ATCC 9092) e os dermatófitos foram Microsporum gypseum (C115), Trichophyton mentagrophytes (ATCC 9972) e Trichophyton rubrum (C137), fornecidos pelo Centro de Referencia en Micologia (CEREMIC) e Facultad de Ciencias Bioquimicas y Farmacéuticas, Suipacha, Rosario, Argentina.

\section{Avaliação da atividade antibacteriana}

Os valores da concentração inibitória mínima (CIM) foram determinados através da diluição 
dos componentes obtidos de $P$. glomerata em ágar empregando a metodologia descrita por National Committee for Clinical and Laboratory Standards (NCCLS, 1993) com modificações. O extrato, frações ou substâncias foram dissolvidas em solução de dimetilsufóxido (DMSO) e água destilada (4:6), foram adicionados em séries de frascos com capacidade para $5 \mathrm{~mL}$ em diferentes concentrações. Em seguida, a cada frasco foi adicionado $1 \mathrm{~mL}$ de meio ágar Mueller-Hinton para as bactérias, seguido de imediata homogeneização da mistura. Após a solidificação dos respectivos meios de cultura, os microrganismos, previamente ativados, foram inoculados nas séries correspondentes, sendo então, incubados a $37^{\circ} \mathrm{C}$ por 18 a 24 horas para as bactérias.

Após o período de incubação, foram realizadas leituras da concentração inibitória mínima através da verificação visual do crescimento microbiano. Para interpretação dos resultados foi considerada CIM a inibição total do crescimento microbiano visível.

Durante os testes foram utilizados controles, com os meios de culturas e solvente utilizado na solubilização do extrato, frações e substâncias, a fim de verificar seu efeito sobre os microrganismos. A concentração final de DMSO nos ensaios não excedeu $2 \%$. A leitura dos resultados foi considerada válida somente quando houve crescimento microbiano nos controles. Os ensaios foram repetidos por três vezes (Souza et al., 2003).

\section{Avaliação da atividade antifúngica}

A CIM de cada extrato, fração ou substância pura foi determinada usando técnicas de microdiluição, de acordo com as normas do NCCLS (2002). Os valores da CIM foram determinados em RPMI-1640 (Sigma) a pH 7.0 com MOPS.

As bandejas foram incubadas a $35{ }^{\circ} \mathrm{C}$ para leveduras e fungos filamentosos e a $28-30{ }^{\circ} \mathrm{C}$ para dermatófitos em uma câmara escura e úmida, e as CIM foram visualmente observadas a $48 \mathrm{~h}$ para leveduras, e para os demais fungos, de acordo com o crescimento do fungo controle. Para os ensaios, soluções estoque de extratos, frações e compostos puros $(100 \mu \mathrm{L})$ foram diluídas 2 vezes com RPMI-1640. Um volume de 100 $\mu \mathrm{L}$ de suspensão do inoculo foi adicionada a cada poço com exceção do controle estéril, onde água foi adicionada a cada poço. Concentrações de 250-0,98 $\mu \mathrm{g} /$ $\mathrm{mL}$ e uma concentração final de DMSO menor ou igual a $2 \%$ foram obtidas nos diferentes poços. A CIM foi definida como a mais baixa concentração do material testado que inibe totalmente o crescimento visual dos fungos comparado ao grupo controle, analisado em triplicata (Zacchino, 2001).

\section{RESULTADOS E DISCUSSÃO}

A atividade antibacteriana do extrato metanólico bruto (EMB) da P. glomerata e das frações Hex, DCM, AE e AQ obtidos na $1^{\text {a }}$ coleta, foi verificada através da determinação da concentração inibitória mínima contra microrganismos patogênicos, cujos resultados estão indicados na Tabela 1. Observou-se que a Fração AE e Fração AQ apresentaram resultados positivos contra Staphylococcus aureus e Escherichia coli. Esta atividade provavelmente se deve à presença de substâncias fenólicas, que segundo a literatura, possuem capacidade de complexar-se a proteínas extracelulares da membrana bacteriana, provocando sua morte (Cowan, 1999). Estudos anteriores demonstraram que várias bactérias são sensíveis a taninos, dentre elas Staphylococcus aureus, Streptococcus pneumonia, Bacillus anthracis e Shigella dysenteriae (Monteiro et al., 2005).

Por outro lado, quando as substâncias isoladas da planta, os taninos [ácido 3,4,3'-trimetóxi-flavelágico4'-O-glicosídeo (1) e ácido 3,4,3'-trimetóxi-flavelágico (2)] foram testadas contra S. aureus e E. coli, revelaramse inativas contra os microrganismos testados até a concentração de $500 \mu \mathrm{g} / \mathrm{mL}$, sugerindo que outras substâncias presentes na planta, provavelmente de natureza fenólica, conforme verificado por CCD e

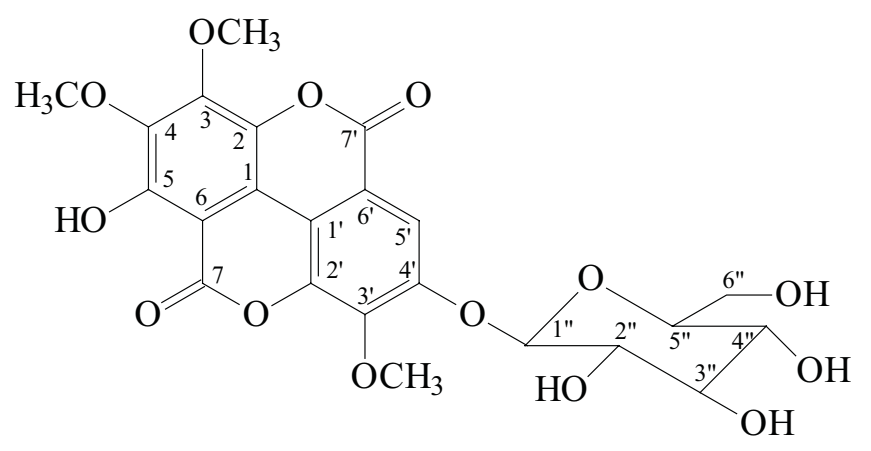

(1)<smiles>COc1cc2oc(=O)c3cc(O)c(OC)c4oc(=O)c(c1O)c2c43</smiles>

(2) 
Tabela 1. Atividade antibacteriana dos extratos, frações e substâncias isoladas de Plinia glomerata, contra os microrganismos patogênicos.

\begin{tabular}{lcc}
\hline & & CIM $(\mu \mathrm{g} / \mathrm{mL})$ \\
\cline { 2 - 3 } Material testado & E.coli & S. aureus \\
\hline EMB & $>1000$ & $>1000$ \\
Fr. Hex & $>1000$ & $>1000$ \\
Fr. DCM & $>1000$ & $>1000$ \\
Fr. AE & $>1000$ & $<500$ \\
Fr. AQ & $500-1000$ & $<500$ \\
(1) & $>500$ & $>500$ \\
(2) & $>500$ & $>500$ \\
\hline
\end{tabular}

Concentração Inibitória Mínima (CIM), Extrato Metanólico Bruto (EMB), Fração hexano (Fr. Hex), Fração diclorometano (Fr. DCM), Fração Acetato de etila (Fr. AE), Fração aquosa (Fr. AQ), Ácido 3,4,3'-trimetóxi-flavelágico-4'-O-glicosídeo (1), Ácido 3,4,3'-trimetóxi-flavelágico (2), Escherichia coli (E. coli), Staphylococcus aureus (S. aureus).

Os experimentos foram realizados em triplicata em três diferentes experimentos.

Tabela 2. Atividade antifúngica dos extratos, frações e substâncias obtidas de Plinia glomerata, contra fungos leveduriformes e filamentosos.

\begin{tabular}{l|c|c|c|c|c}
\hline \multirow{2}{*}{ Fungo } & \multicolumn{5}{|c}{ CIM $(\mu \mathrm{g} / \mathrm{mL})$} \\
\cline { 2 - 6 } & EA & EM & AQ & $(1)$ & $(2)$ \\
\hline Candida albicans & $>250$ & $>250$ & $>250$ & $>250$ & $>250$ \\
Candida tropicalis & $>250$ & $>250$ & $>250$ & $>250$ & $>250$ \\
Saccharomyces cerevisiae & $>250$ & $>250$ & $>250$ & $>250$ & $>250$ \\
Cryptococcus neoformans & $>250$ & $>250$ & $>250$ & $>250$ & $>250$ \\
Aspergillus fumigatus & $>250$ & $>250$ & $>250$ & $>250$ & $>250$ \\
Aspergillus flavus & $>250$ & $>250$ & $>250$ & $>250$ & $>250$ \\
Aspergillus niger & $>250$ & $>250$ & $>250$ & $>250$ & $>250$ \\
Microsporum gypseum & 125 & 250 & 250 & $>250$ & $>250$ \\
Trichophyton mentagrophytes & 125 & 125 & 125 & $>250$ & $>250$ \\
Trichophyton rubrum & 125 & 125 & 125 & $>250$ & $>250$ \\
\hline
\end{tabular}

Concentração Inibitória Mínima (CIM), Extrato acetônico (EA), Extrato metanólico (EM), Fr. aquosa (AQ), Ácido 3,4,3'-trimetóxi-flavelágico-4'-O-glicosídeo (1), Ácido 3,4,3'-trimetóxi-flavelágico (2).

Os experimentos foram realizados em triplicata em três diferentes experimentos.

reagente específico $\left(\mathrm{FeCl}_{3}\right)$, estão atuando contra os microrganismos ou devido a existência de sinergismo.

A atividade antifúngica do extrato acetônico, metanólico ( $2^{\mathrm{a}}$ coleta) e aquoso ( $1^{\mathrm{a}}$ coleta) também foi analisada através da determinação da concentração inibitória mínima contra fungos leveduriformes e filamentosos, cujos resultados estão indicados na tabela 2. Observou-se que os extratos acetônico, metanólico e aquoso foram bem efetivos contra Thichophyton mentagrophytes e T. rubrum com CIM de $125 \mu \mathrm{g} / \mathrm{mL}$. Já o extrato acetônico demonstrou a melhor atividade contra Microsporum gypseum, apresentando uma CIM de $125 \mu \mathrm{g} / \mathrm{mL}$.

Apesar de verificarmos nos extratos ou frações uma tendência à atividade antimicrobiana, as substâncias isoladas, identificadas como ácido 3,4,3'-trimetóxiflavelágico-4'-O-glicosídeo (1) e ácido 3,4,3'-trimetóxiflavelágico (2), não demonstraram atividade, indicando que não são ativas até a concentração máxima analisada, e provavelmente outros compostos são responsáveis pela atividade antimicrobiana dos extratos e frações, não descartando-se a possibilidade de sinergismo entre as moléculas presentes nos extratos. Embora os estudos científicos desta planta sejam raros, os resultados obtidos confirmam e complementam os estudos anteriormente realizados por Silva et al. (2000) sobre o potencial antimicrobiano de $P$. glomerata. 


\section{CONCLUSÃ̃}

As frações mais polares apresentaram efeitos antimicrobianos contra a bactéria Staphylococcus aureus (AE e AQ), enquanto os extratos EA e EM, além da fração $\mathrm{AQ}$, foram efetivos contra os fungos Aspergillus fumigatus, Trichophyton mentagrophytes e Trichophyton rubrum. Das substâncias isoladas 1 e 2 e submetidas à investigação antimicrobiana, nenhuma demonstrou atividade até a concentração de $500 \mu \mathrm{g} / \mathrm{mL}$, sugerindo que outras substâncias presentes na planta estão atuando contra os microorganismos testados ou existe sinergismo entre as substâncias ocasionando o efeito antimicrobiano evidenciado pelos extratos e frações testadas.

\section{AGRADECIMENTOS}

Os autores agradecem ao Dr. Eliseo Soprano (Epagri-SC) pela coleta do material vegetal e ao Professor Oscar Iza (HBR e UNIVALI) pela classificação botânica da planta. Agradecem também à Rede RIBIOFAR RT 0284/Cyted, FAPESC-SC, ao CNPq e à ProPPEC/ UNIVALI pelo auxílio financeiro. SZ agradece a ANPCyT PICT R 260 e Projeto X.7-CYTED. MAG agradece ao CONICET pela bolsa de doutorado.

\section{REFERÊNCIAS}

Agra MF, França PF, Barbosa-Filho JM 2007. Synopsis of the plants known as medicinal and poisonous in Northeast of Brazil. Rev Bras Farmacogn 17: 114-140.

Amaral FMM, Ribeiro MNS, Barbosa-Filho JM, Reis AS, Nascimento FRF, Macedo RO 2006. Plants and chemical constituents with giardicidal activity. Rev Bras Farmacogn 16(Supl.): 696-720.

Barbosa-Filho JM, Vasconcelos THC, Alencar AA, Batista LM, Oliveira RAG, Guedes DN, Falcão HS, Moura MD, Diniz MFFM, Modesto-Filho J 2005. Plants and their active constituents from South, Central, and North America with hypoglycemic activity. Rev Bras Farmacogn 15: 392-413.

Bezerra JL, Costa GC, Lopes TC, Carvalho ICDS, Patrício FJ, Sousa SM, Amaral FMM, Rebelo JMM, Guerra RNM, Ribeiro MNS, Nascimento FRF 2006. Avaliação da atividade leishmanicida in vitro de plantas medicinais. Rev Bras Farmacogn 16(Supl.): 631-637.

Bnouham M, Ziyyat A, Mekhfi H, Tahri A, Legssyer A 2006. Medicinal plants with potential antidiabetic activity - A review of ten years of herbal medicine research (1990-2000). Int J Diabetes Metabolism 14: 1-25.

Cabeludinha 2005. http://www.esalq.usp.br/trilhasfruti/fr08. $\mathrm{htm}$, acessado em fevereiro de 2005.

Cechinel Filho V, Yunes RA 1998. Estratégias para obtenção de compostos farmacologicamente ativos a partir de plantas medicinais. Conceitos sobre modificação estrutural para otimização da atividade. Quim Nova 21: 99-105.

Cowan MM 1999. Plant products as antimicrobial agents. Clin
Microbiol 12: 564-582.

Gibbons S 2003. An overview of plants extracts as potential therapeutics. Exp Opin Ther Patents 13: 489-497.

Monteiro JM, Albuquerque UP, Araujo EL, Cavalcanti de Amorin EL 2005. Taninos: uma abordagem de química à ecologia. Quim Nova 28: 892-896.

Morais SM, Dantas JDP, Silva ARA, Magalhães EF 2005. Plantas medicinais usadas pelos índios Tapebas do Ceará. Rev Bras Farmacogn 15: 169-177.

NCCLS 1993. National Committee for Clinical and Laboratory Standards. Methods for dilution antimicrobial susceptibility tests for bacterial that grow aerobically, document M7-A3. Wayne, Pa: National Committee for Clinical and Laboratory Standards.

NCCLS 2002. National Committee for Clinical and Laboratory Standards. Performance standards for antimicrobial susceptibility testing. Twelfth informational supplement. NCCLS document M100-12. National Committee for Clinical and Laboratory Standards, Wayne, $\mathrm{Pa}$.

Niero R, Malheiros A, Bittencourt CMS, Biavatti MW, Leite SN, Cechinel Filho V 2003. Aspectos químicos e biológicos de plantas medicinais e considerações sobre fitoterápicos. In: Bresolin TMB, Cechinel Filho V. (org.) Ciências Farmacêuticas: contribuição ao desenvolvimento de novos fármacos e medicamentos. Itajaí: Ed. Univali, p.10-56.

Oliveira FQ, Gobira B, Guimarães C, Batista J, Barreto M, Souza M 2007. Espécies vegetais indicadas na odontologia. Rev Bras Farmacogn 17: 466-476.

Serafin C, Nart V, Malheiros A, de Souza MM, Fischer L, Delle Monache G, Delle Monache F, Cechinel Filho V. F 2007. Bioactive phenolic from aerial parts of Plinia glomerata. Z Naturforsch 62c: 196-200.

Silva MG, Ohara MT, Kato ETM, Maia JGF, Andrade EH, Yoshida M 2000. Estudo farmacognóstico de Myrciaria glomerata. XVI Simpósio de Plantas Medicinais do Brasil, Recife, Brasil.

Souza MM, Bella Cruz AB, Schuhmacher MB, Kreuger MRO, Freitas RA, Bella Cruz RC 2003. Métodos de avaliação de atividade biológica de produtos naturais e sintéticos. In: Bresolin TMB, Cechinel Filho V(org.) Ciências Farmacêuticas: contribuição ao desenvolvimento de novos fármacos e medicamentos. Itajaí: Ed. Univali, p. 108-166.

Vendruscolo GS, Rates SMK, Mentz LA 2005. Dados químicos e farmacológicos sobre as plantas utilizadas como medicinais pela comunidade do bairro Ponta Grossa, Porto Alegre, Rio Grande do Sul. Rev Bras Farmacogn 15: 361-372.

Zacchino S 2001. Estratégias para a descoberta de novos agentes antifúngicos. In:Yunes, RA, Calixto JB (ed.), Plantas medicinais sob a ótica da química medicinal moderna. Chapecó: Ed. Argos, p. 435-479. 